\title{
Clinical evaluation of techniques used in the surgical treatment of progressive hemifacial atrophy
}

\author{
Roberto Roddi ${ }^{1}$, Egidio Riggio ${ }^{2}$, Philip M. Gilbert ${ }^{1}$, Steven E. R. Hovius ${ }^{1}$, J. Michiel Vaandrager ${ }^{1}$, \\ Jacques C. H. van der Meulen ${ }^{1}$ \\ ${ }^{1}$ Department of Plastic and Reconstructive Surgery (Head: Prof. Dr J. C. H. van der Meulen, MD, PhD) \\ University Hospital Rotterdam, Dijkzigt and Sophia Children's Hospital Rotterdam, The Netherlands, \\ ${ }^{2}$ Department of Plastic and Reconstructive Surgery (Head: Prof. Dr A. Azzolini, MD) University Hospital \\ Milan, S. Donato Hospital, Milan, Italy
}

\begin{abstract}
$S U M M A R Y$. We critically review 13 patients with progressive hemifacial atrophy treated with three basic surgical procedures (free flap transplantation, alloplastic implants, micro-fat injections 'lipofilling') and further ancillary techniques. In spite of the satisfactory results achieved with the procedures, with the exception of alloplasts, we feel that lipofilling may be considered an interesting solution for soft tissue augmentation of the face especially for moderate adipose defects, due to its repeatability, no donor site morbidity, no complications at the recipient site such as lesions resulting from dissection, bleeding, necrosis, etc. This technique can be performed in a day-hospital with short surgery time, at low cost and without a highly skilled team. For severe grades of adipose atrophy, because of the low blood supply to these tissues which interferes with take of any type of autograft, we think that free flaps actually represent one of the best solutions for soft tissue augmentation.
\end{abstract}

\section{INTRODUCTION}

Progressive hemifacial atrophy (PHA) is an uncommon acquired affliction of the soft tissues of the face. This disease, described by Parry (1825) and Romberg (1846) was called 'progressive facial hemiatrophy' by Eulenburg (1871). Several theories have tried to explain the aetiopathogenesis of this atrophy but none has clearly defined the nature of this disease. The onset is slow and progressive, starting at 5-15 years of age and lasting from 2-10 years, thereafter the disease appears to 'burn itself out'. The atrophy seems to affect females more than males, bilateral incidence is almost $5 \%$. Bone hypoplasia occurs in severe cases. Treatment of this facial deformity is at present exclusively symptomatic and does not involve the disease process itself.

Various surgical procedures have been adopted in the past, and the earliest to be evaluated was fat grafting which has been used since the last century (van der Meulen, 1889; Neuber, 1893). Neuber used fat autografts for soft tissue depressions with excellent aesthetic results, preferring small rather than large grafts. Lexer (1910) first used it in the facial region. Peer (1956) maintained that it was the best material for facial contouring in patients with hemiatrophy, microsomia and lipodystrophy. The physiological and clinical behaviour of fat grafts was well studied by Peer (1956) and reviewed by Billings and May (1989). It should be pointed out that fat autografts vascularize from the fourth day, an inflammatory reaction with macrophages reaches a peak at 2 months and decreases up to 8 months, normal adipose tissue is present 1-2 years later, surrounded by a thick fibrosis but there is no replacement with scar tissue, some fat resorption usually occurs within 1 year and varies from $30-60 \%$ in patients followed up for $1-3$ years in accordance with Peer (1956), Sokolova (1972), Saunders et al. (1981), Illouz (1985; 1986), Chajchir et al. (1990), Antoine (1990), Horl et al. (1991). However, because of this reduced survival, the fat graft was neglected and the method replaced, by the use of silicone and other alloplastic materials, promoted as modern inert implants for recontouring (Kiskadden and McGregor, 1946; Ashley et al., 1965; Pearl et al., 1978; Franz et al., 1988; Nerobyeyev et al., 1990). Nevertheless surgeons continued to use fatty tissue, including it in dermal fat grafts (Kazanjian and Sturgis, 1940; Peer, 1956; Peskova and Stockar, 1961; Sokolova, 1972; Hurwitz and Sarel, 1982; Jackson et al., 1986). Ellenbogen (1986) used free pearl fat autografts with a diameter of 4-6 mm. Facial atrophy has also been treated by flap reconstruction. Rogers (1964) considered the pedicled flap to be the best choice (Neumann, 1953; Peskova and Stockar, 1961; Converse and Betson, 1971; Pitanguy et al., 1971; Sharpe, 1971). Free omentum (Upton et al., 1980; Jurkiewicz and Nahai, 1985), groin (Harashina et al., 1977; Wells and Edgerton, 1977; Anderl, 1979; Dunkley and Stevenson, 1990; Smith and Manktelow, 1990), rectus abdominis (Jackson et al., 1986), parascapular (Nassif et al., 1982), radial forearm, and latissimus dorsi (Horl et al., 1991) flaps have all been used in the last decade. Furthermore bone temporalis flaps have been reported to fill hard tissue defects of the face (Cutting et al., 1984; van der Meulen et al., 1984; Fukuta et al., 1991). Good results are reported when the free serratus anterior flap is used. In this. 


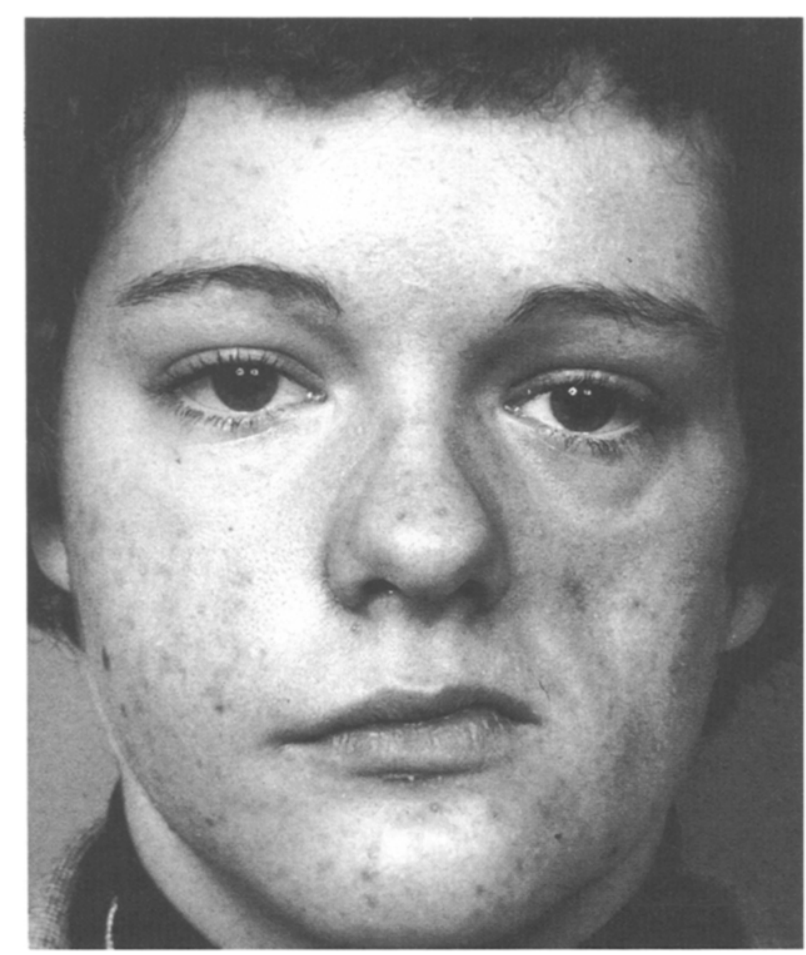

A

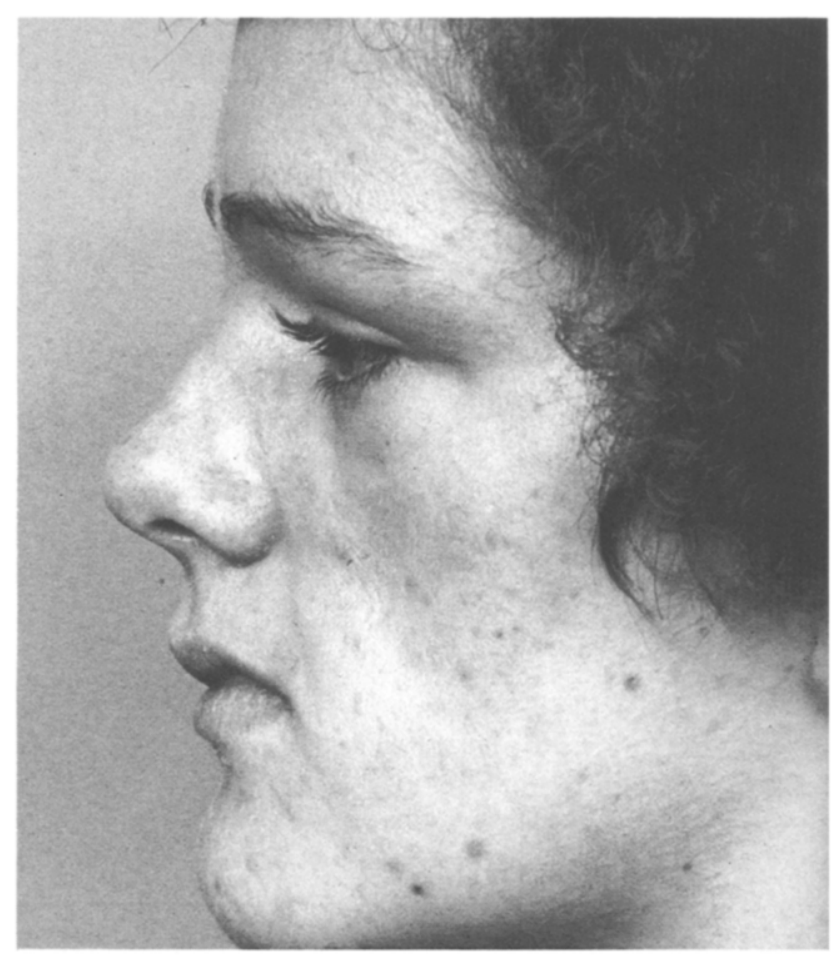

B

Fig. 1 - Case 1. Pre-operative clinical view of a patient with PHA that involves the left side of the face. (A) Frontal view, (B) lateral view (left).

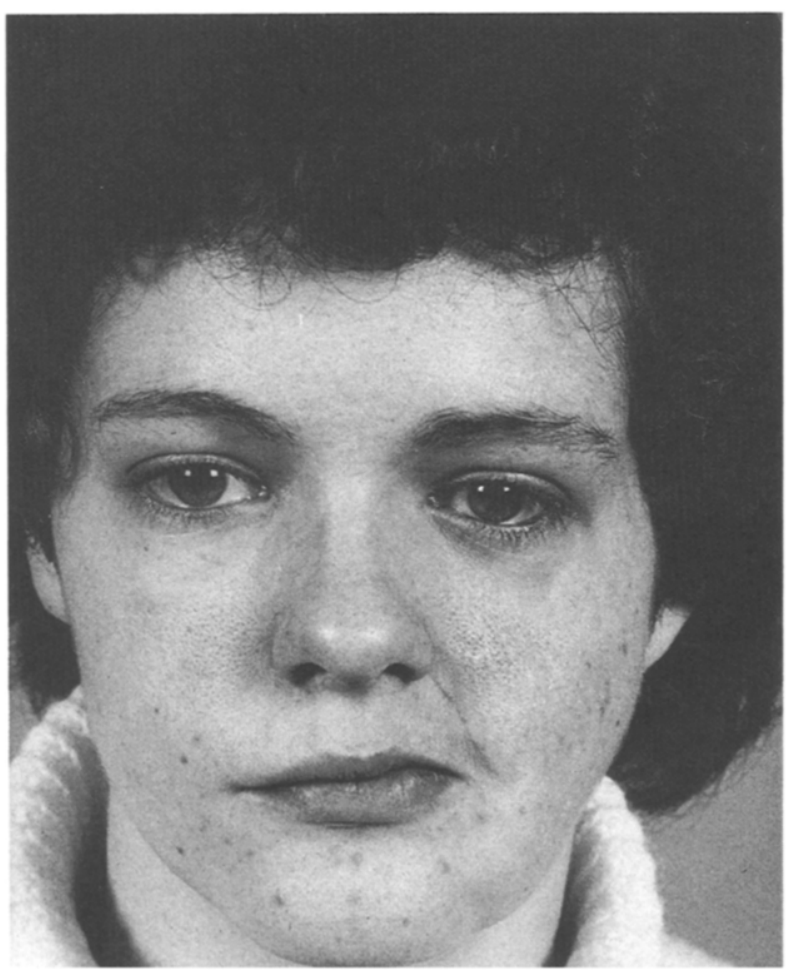

A

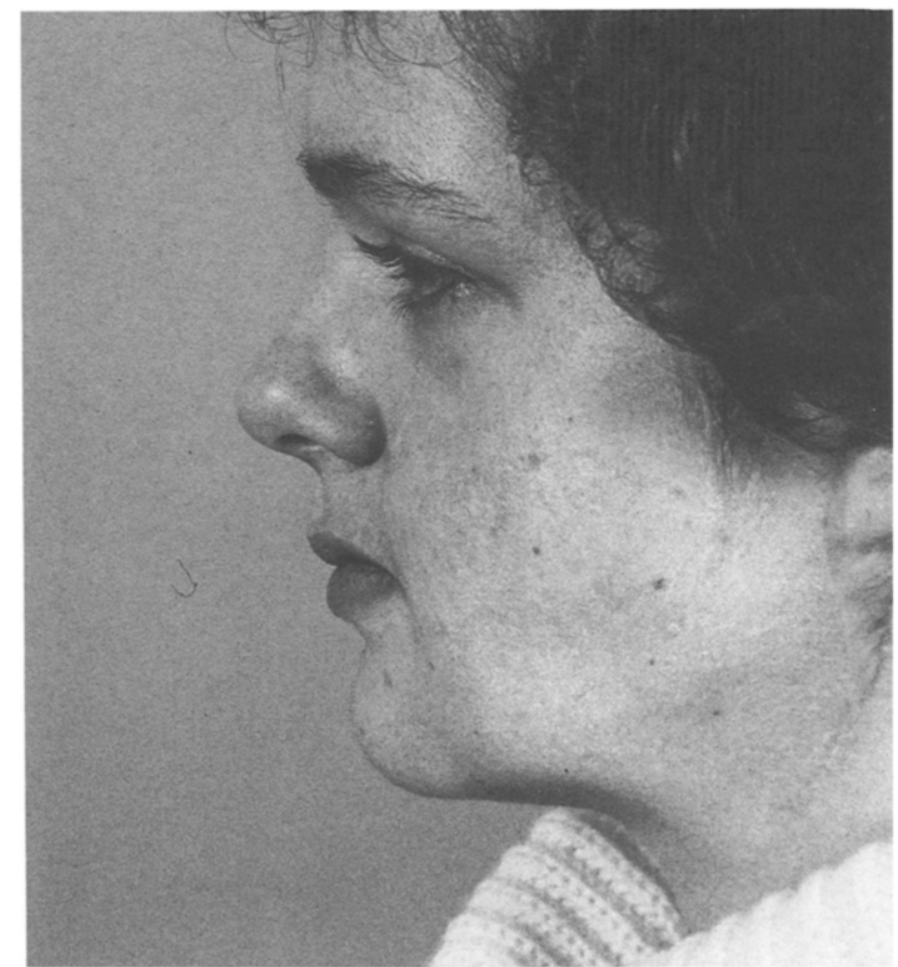

B

Fig. 2 - Case 1. Postoperative view of the patient after correction of facial deformity with a free groin flap. (A) Frontal view, (B) lateral view (left). 

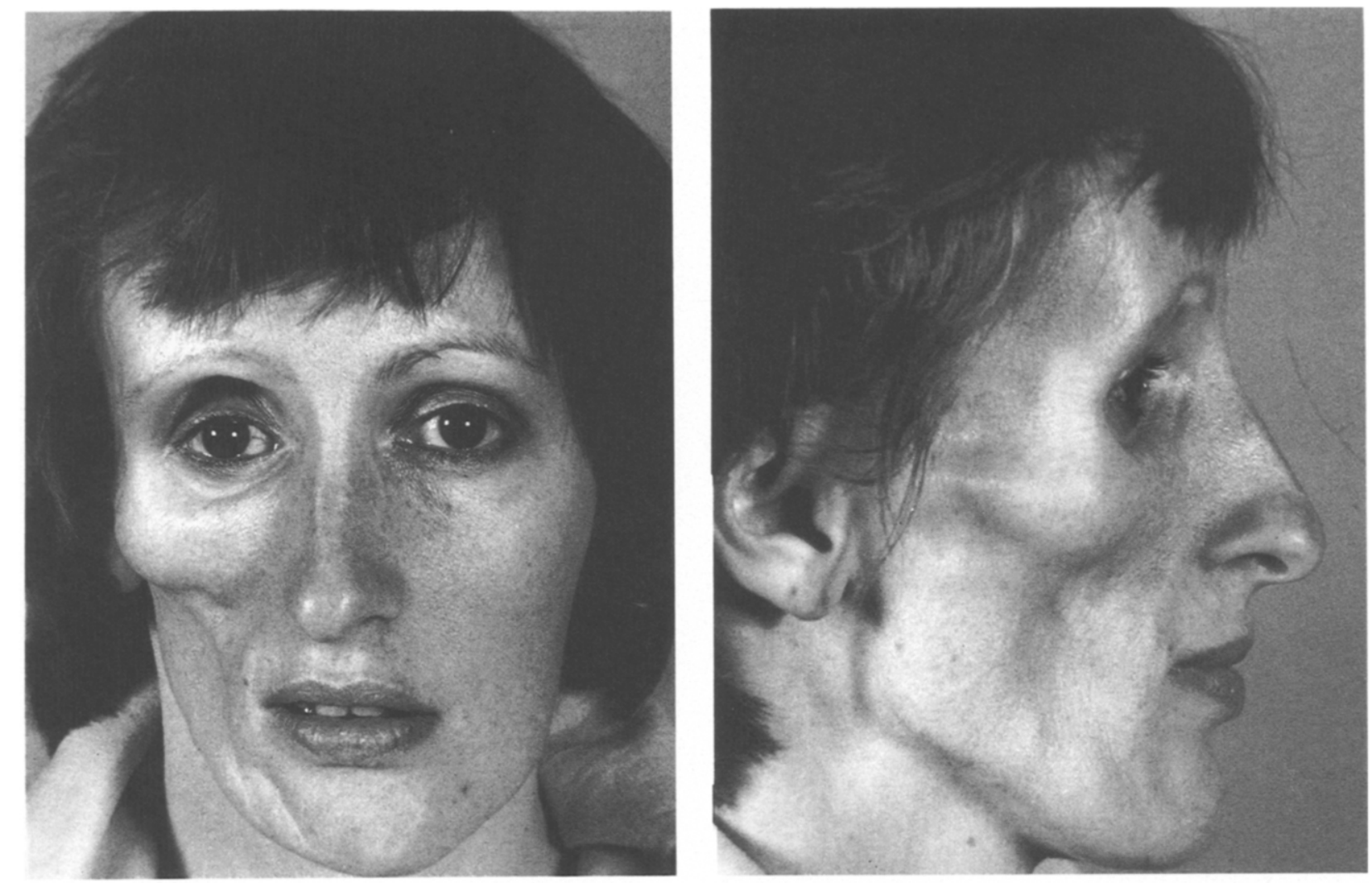

A

B

Fig. 3 - Case 2. Pre-operative clinical view of a patient with PHA involving the right side of the face. (A) Frontal view, (B) lateral view (right).

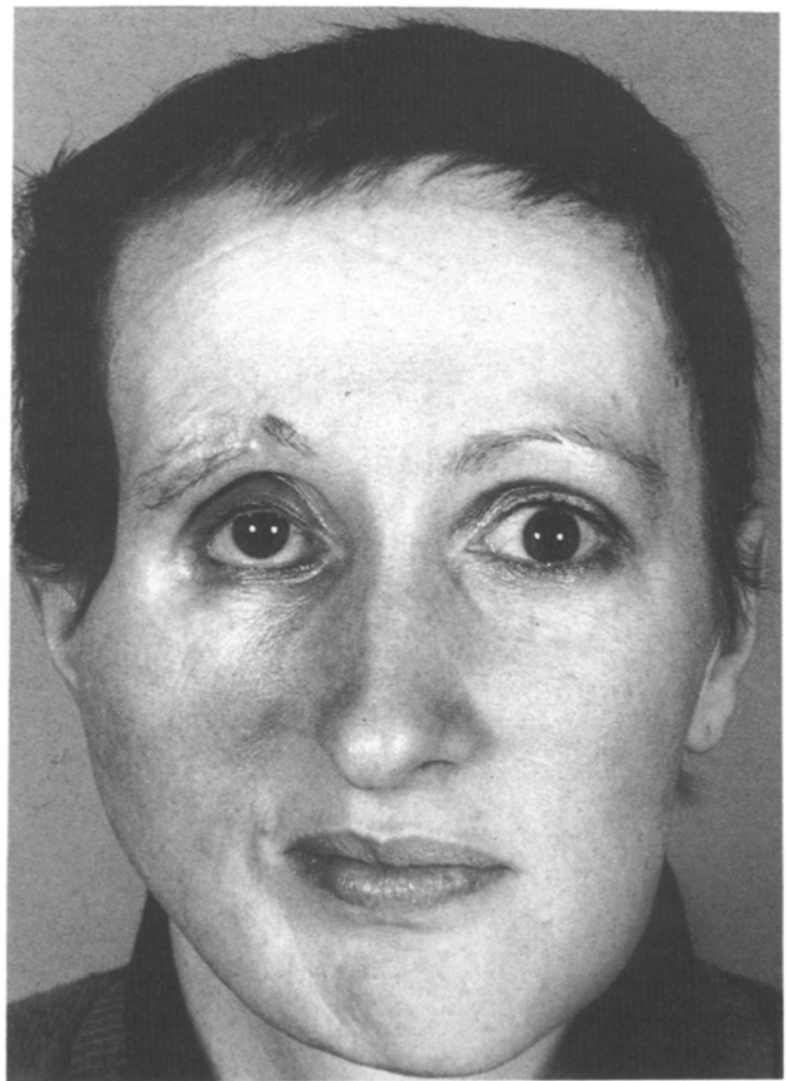

A

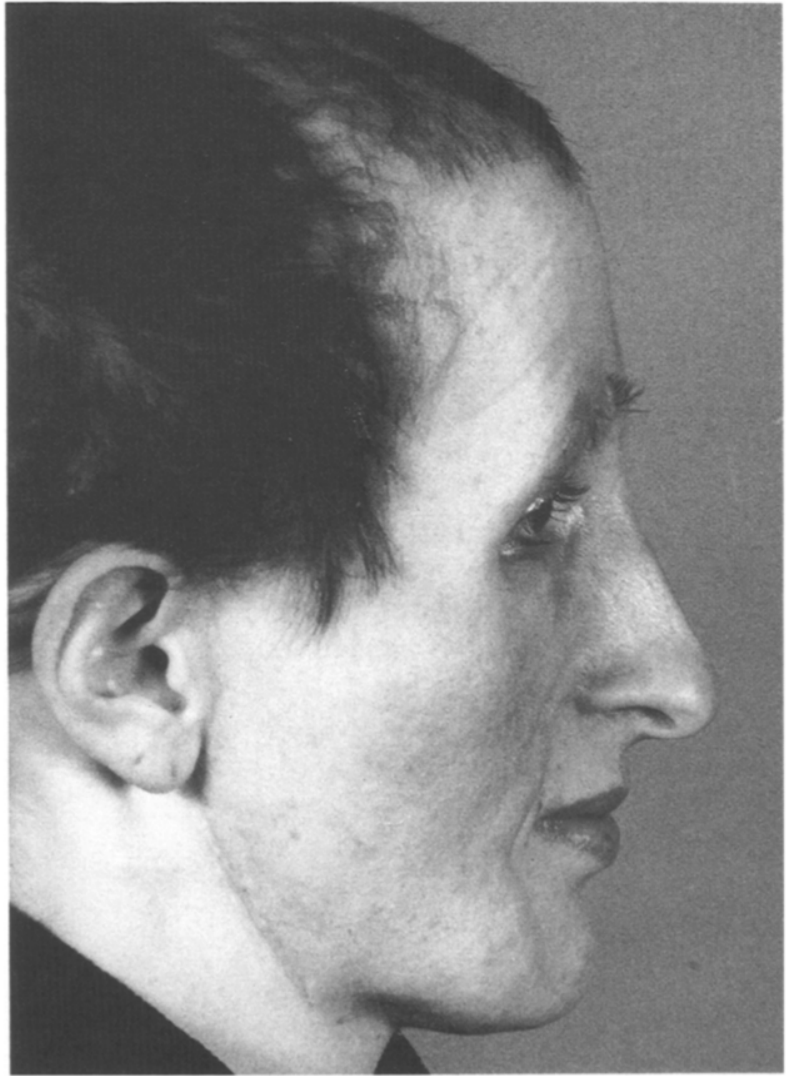

B

Fig. 4 -Case 2. Postoperative view after correction with a free latissimus dorsi muscle flap. (A) Frontal view, (B) lateral view (right). 


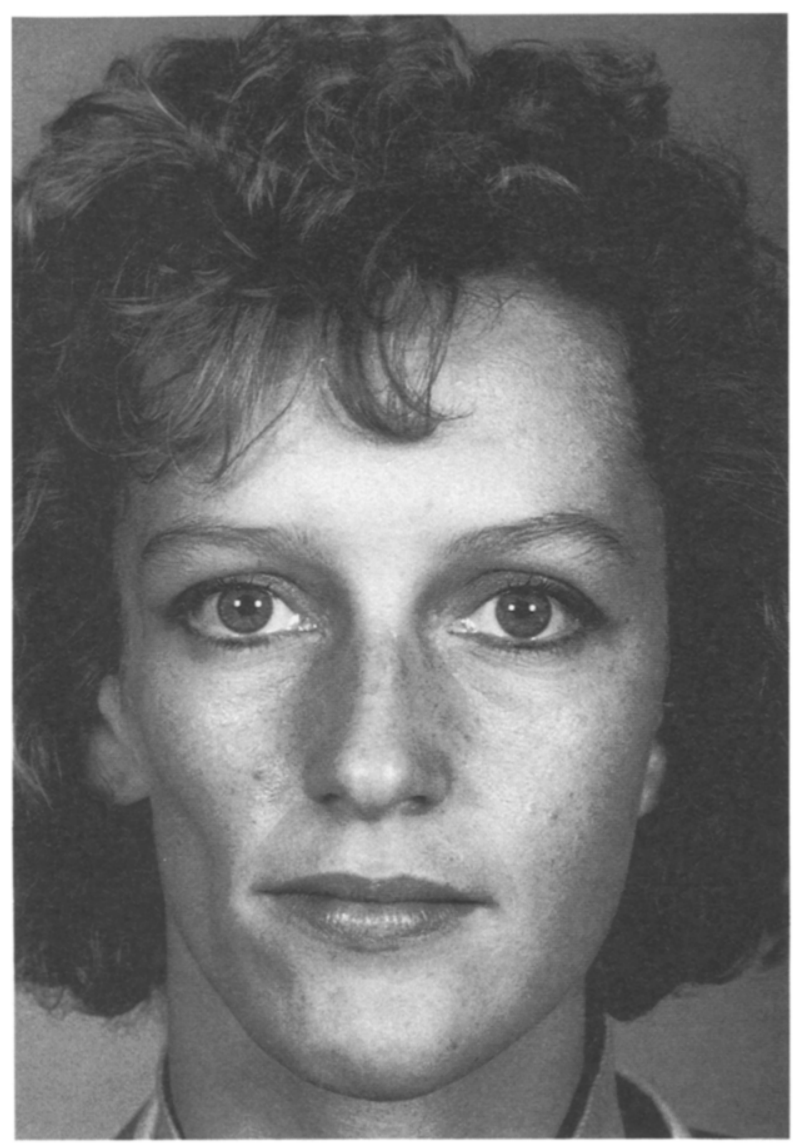

A

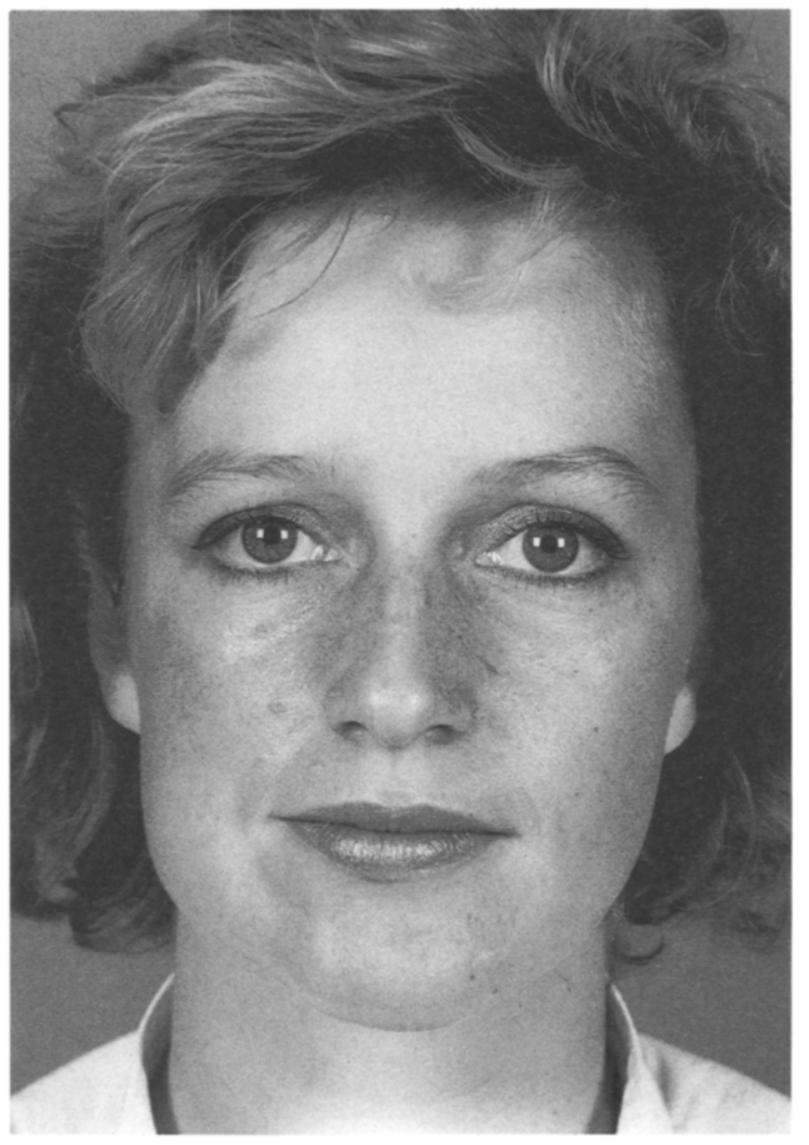

B

Fig. 5 - Case 3. Pre-operative clinical view of a patient with PHA involving the right side of the face. (A) Frontal view. (B) Postoperative view of the patient. In this case the facial deformities were corrected with a free radial forearm flap. (Frontal view.)

case, the donor site scar on the lateral chest wall is not very aesthetic but overall it seems to be one of the best.

Other procedures available to the reconstructive surgeon include bone grafts and advancement osteotomies in cases of severe deficit. The innovative procedure of lipo-aspiration by suction changed the old concept of free fat grafting. By means of liposuction, Illouz (1985), Fournier (1985), Asken (1988) and Chajchir (1990) et al. could harvest small amounts of adipocytes (cellular culture-grafts) instead of grafts of organized fatty tissue and renewed interest in this grafting technique, using microlipo-injections for soft tissue replacement. Indeed Bruning in 1911 had already used a syringe to inject small cubes of fatty tissue under nasal skin but he reported long-term failures.

\section{MATERIALS AND METHODS}

\section{Clinical features}

A total of 11 female and 2 male patients with PHA have been treated from 1975 to 1992 . The female/male ratio is $5.5: 1(\mathrm{p}<0.01)$. The mean age at the first surgical treatment was 25.7 years \pm 7.9 (range 16-41). Times of onset, progression and 'burn out' of the disease were respectively 13.3 years \pm 9.24 (range
4-33), 8 years \pm 2.78 (range 4-12), 21 years \pm 7.39 (range 12-40). The right side was affected in 5 patients, the left side in 6 , and bilaterally in 2 patients. The soft tissue atrophy initially appeared in the frontal region in 7 cases, maxillary region in 6 cases, and mandibular region in 4 cases. While in the definitive onset the frontal region was affected in 8 patients, maxillary region in all 13 patients, and mandibular region in 9 of them.

The types of skin lesion seen were scleroderma in 6 cases, coup de sabre in 5 cases, alopecia in 4 cases, and hypo/hyperpigmentation in 4 cases. Of the patients with alopecia, in 3 cases it involved the fronto-parietal and eyebrow areas, and in 1 case the temporooccipital area. Radiographic investigation revealed bone involvement - mainly of mild form-in 6 cases with almost uniform distribution among frontal, maxillary and mandibular regions. Atrophy involved the alar cartilage of the nose ipsilaterally in 4 cases, temporal muscle in 2 cases, and the arm in 2 cases.

Neuropathies were found in 6 patients as follows: headache in 3 cases (hemicranical in 2 and diffuse in 1), contralateral Jacksonian epilepsy in 1 case and 'petit mal' in 1 case, contralateral facial palsy in 2 cases, sympathetic disorders (mydriasis in 1 case), facial spasm in 1 case, ataxia in 1 case, and glioma in 1 case. Ophthalmopathies occurred in 4 patients: 


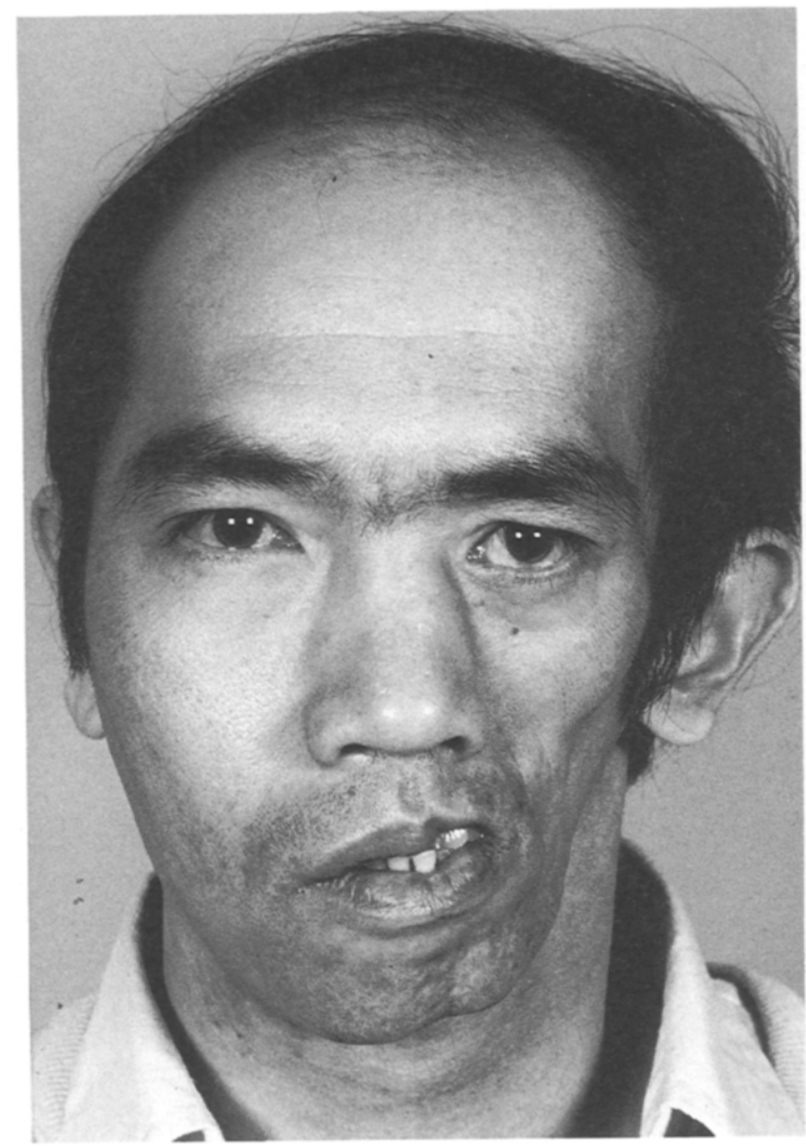

A

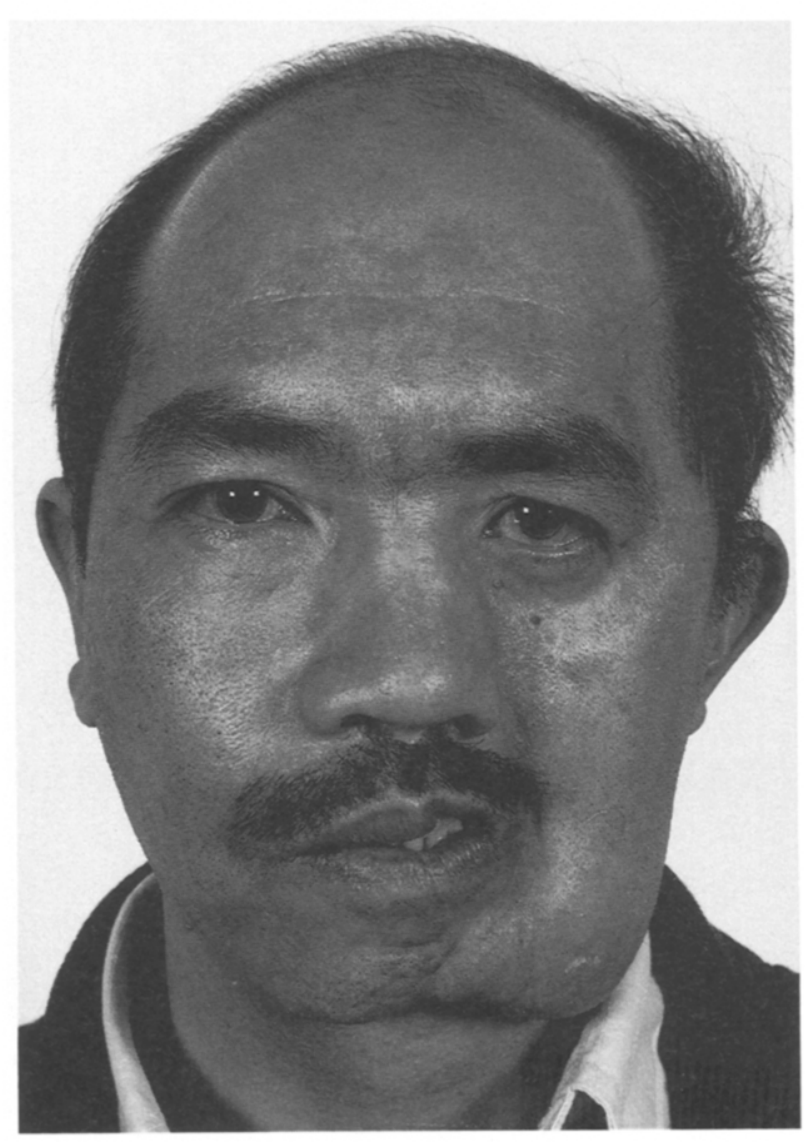

B

Fig. 6-Case 4. (A) Pre-operative clinical view of a patient with PHA involving the left side of the face; frontal view. (B) Postoperative view after free parascapular flap transfer. In this patient a maxillary osteotomy (Le Fort I type) and a mandibular osteotomy (bilateral sagittal split) for correction of dento-facial deformities were also performed; frontal view.

enophthalmos in 3 cases, convergent strabismus in 3 cases, lagophthalmos in 2 cases, fundus vascular anomalies in 1 case. The association with autoimmune disease was seen in one case with lupus erythematosus.

\section{Surgical procedures}

The patients were treated using one of three basic reconstructive techniques: free flap transfer, lipofilling, implantation of alloplastic materials.

\section{Free microvascularized flap transfer}

The following free flaps were used in 5 patients: two groin (Fig. 1A, B; 2A, B), one latissimus dorsi (Fig. $3 \mathrm{~A}, \mathrm{~B} ; 4 \mathrm{~A}, \mathrm{~B}$ ), one forearm (Fig. 5A, B), and one parascapular (Fig. 6A, B).

The size needed for augmentation depends on the volume of soft tissue defect. The skin incision was preauricular prolonged along the mandibular angle. The flaps were fixed to the malar periosteum and dermis with non-absorbable sutures. The recipient artery was in every case the facial artery and the veins were the facial and external jugular veins; end-to-end anastomoses were performed. Postoperative flap survival was monitored by telethermometry and laser Doppler flowmetry. No vascular complications were observed.

The groin flap is de-epithelialized for soft tissue augmentation and its adipose component is sufficient for severe facial deformities. In both cases in which groin flaps were used revisions were required on three occasions, for flap suspensions 1 year after the operations and one defatting procedure after 6 years.

The latissimus dorsi flap was used as muscle alone. No revision has been needed in 8 years.

The radial forearm flap has a thin adipose layer. A de-epithelialized flap was used. No revision has been necessary in 5 years.

A de-epithelialized parascapular flap has been used once. No revision has been needed in two years.

\section{Lipofilling}

Lipofilling has been used in 6 cases in the microlipoinjection form, harvesting fat from the para-umbilical, hip or external side of the thigh, and injecting it through the same syringe without handling the fragile fat further (Fig. 7A, B; 8A, B). The operation was performed under general anaesthesia and antibiotic cover was started $30 \mathrm{~min}$ before surgery, e.g. amoxycillin $1200 \mathrm{mg} 4$ times a day for $48 \mathrm{~h}$. A cannula (2-3 mm calibre, $12 \mathrm{~cm}$ length, 3 blunt openings) 

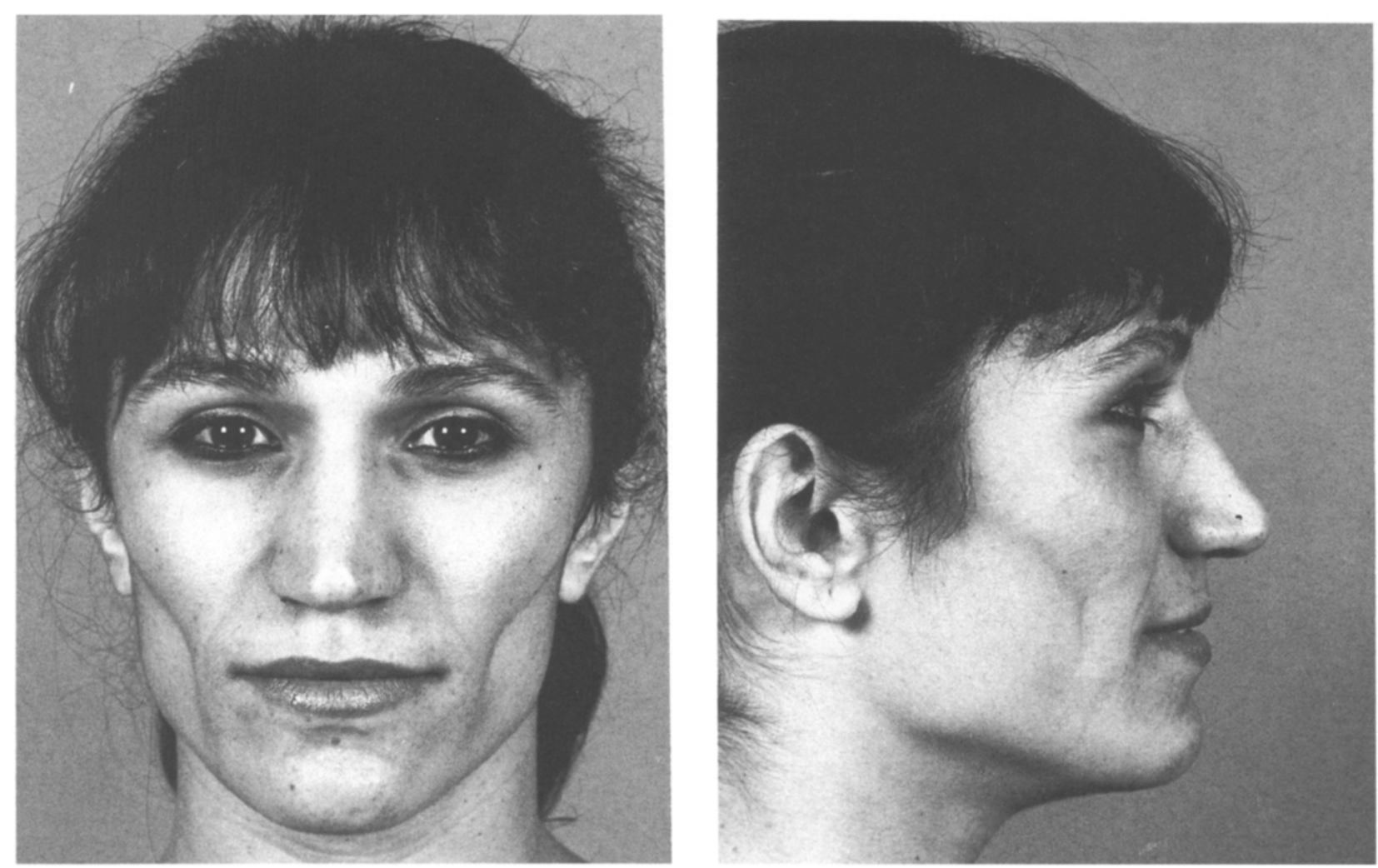

A

B

Fig. 7 - Case 5. Pre-operative clinical view of a patient with a bilateral form of PHA. (A) Frontal view, (B) lateral view (right).

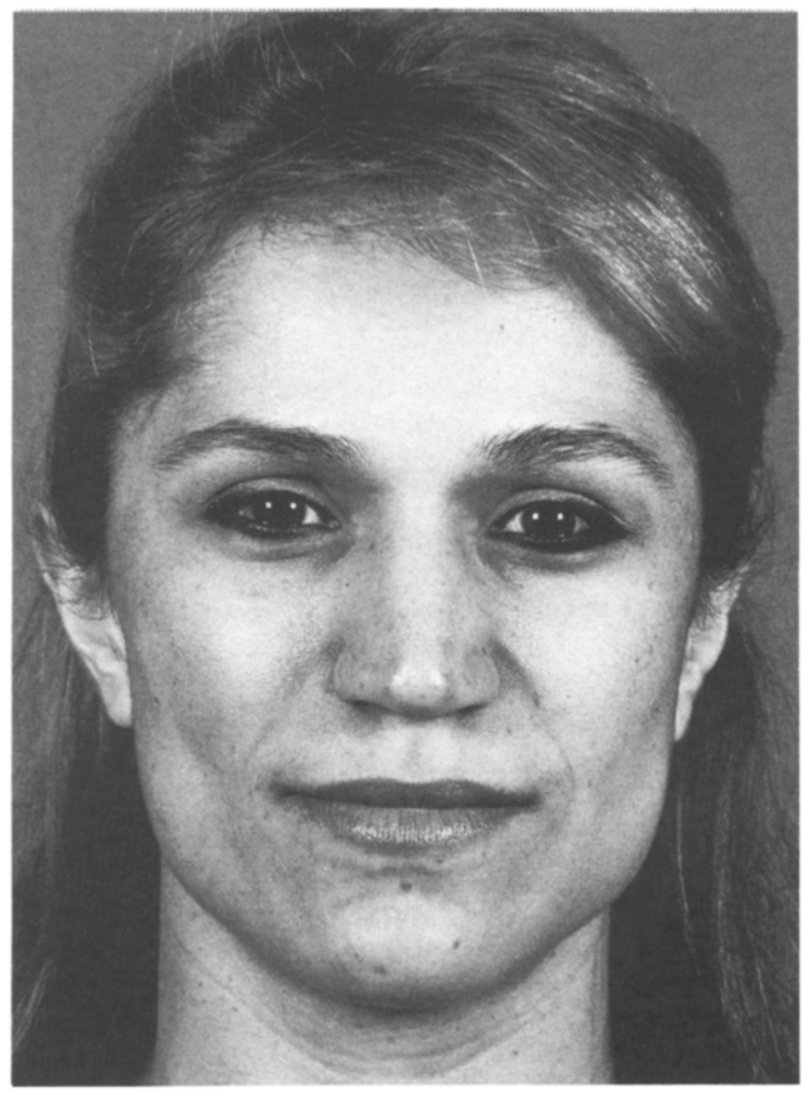

A

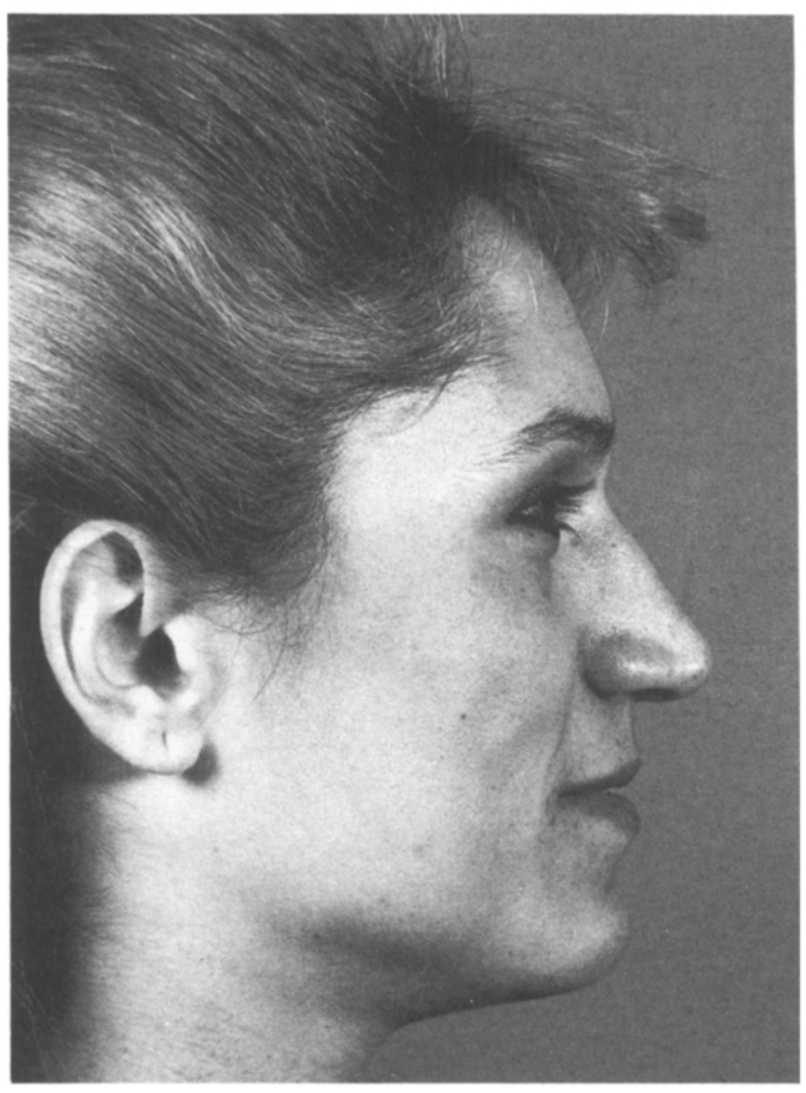

B

Fig. 8 - Case 5. Postoperative view 1 year after correction with lipofilling. (A) Frontal view, (B) lateral view (right). 


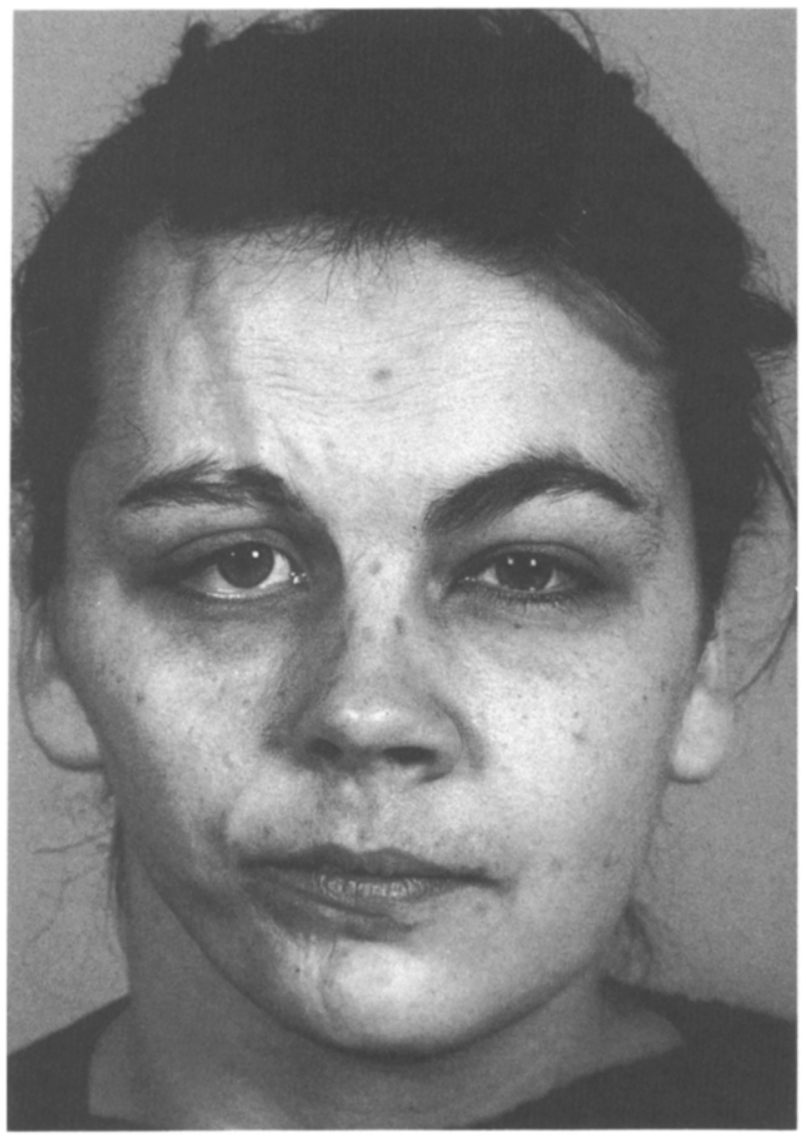

A

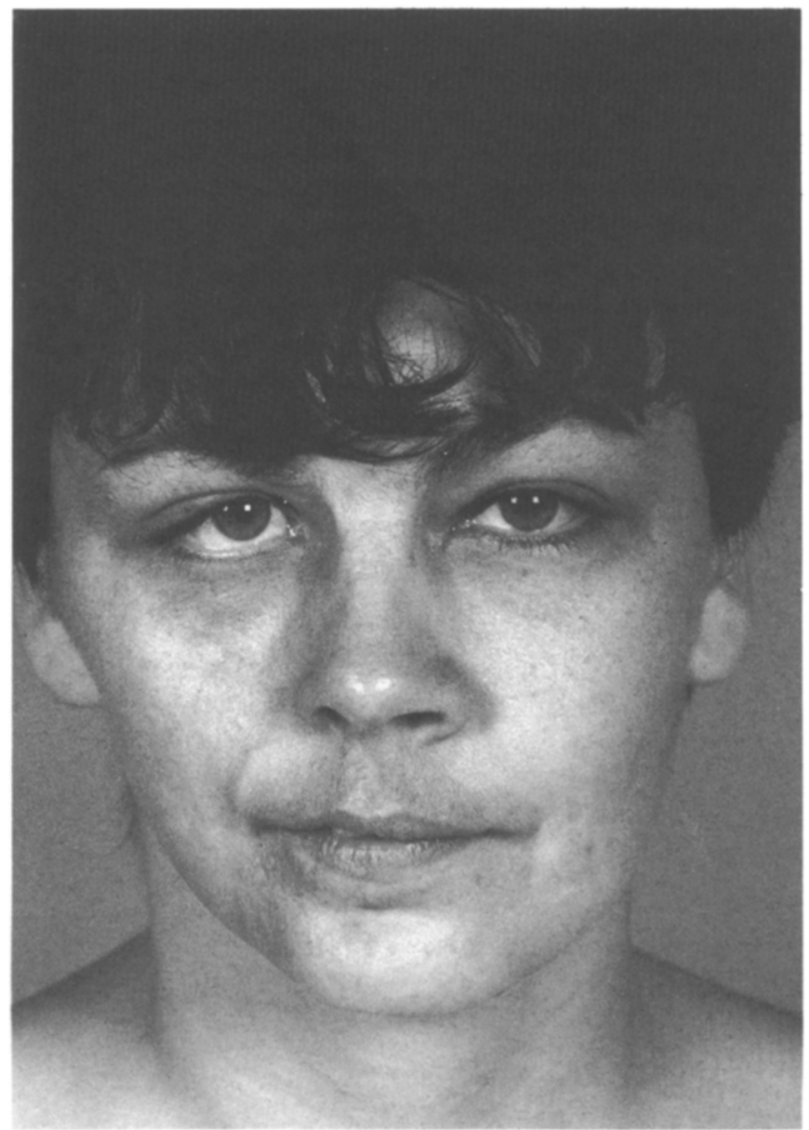

B

Fig. 9 - Case 6. (A) Pre-operative view of a patient with PHA involving the right side of the face; frontal view. (B) Postoperative view of the patient ( 1 year) after multiple dermal graft and collagen injections and chondroplast implantation; frontal view.

connected to a disposable syringe $(20-60 \mathrm{cc})$ was introduced into the donor area through a skin incision of almost $3 \mathrm{~mm}$. The vacuum was obtained by pulling and stopping the plunger of the syringe with a locking system (LS Pointoise, France), without using a suction machine. Using the same syringe, fat was transferred to the recipient area through an atraumatic needle ( $2 \mathrm{~mm}$ calibre, $4 \mathrm{~cm}$ length) perforating the skin at the hair line or at a pre-auricular site. The fat was injected in small amounts (nearly $1 \mathrm{cc}$ per $1 \mathrm{~cm}^{2}$ of soft tissue surface) subcutaneously, in one layer only, while withdrawing the needle. No manipulation or treatment of the fat was carried out. Between 20 and $60 \mathrm{cc}$ of fat were injected at each sitting. The operation is contraindicated in the following circumstances: heavy smokers, psycholabile patients, obesity, diabetes and other endocrine disorders, active collagenvascular disease.

Furthermore, ancillary techniques have been used in 7 patients, as bone grafts in order to correct enophthalmos and bone contour defects; Le Fort 1 and sagittal split mandibular osteotomies, and osteogaleal temporal flap for bone augmentation; dermal grafts, collagen injections, chondroplast for mild defects (Fig. 9A, B); skin expanders for frontal atrophic skin and alopecia; etc.

\section{Alloplastic implants}

Two patients had silicone prostheses for frontal and maxillary augmentation, of which one was removed after 6 months because of patient dissatisfaction. Polymethylmethacrylate was implanted twice in 1 patient and in another case where subsequent removal ( 2 years later) was required due to infection.

The follow-up is respectively a mean of: 8.2 years \pm 4.8 (range 2.2-13) for 5 free flaps; 11.5 months \pm 5.99 (range $3-18$ ) for 6 lipofilling, and 6.5 years \pm 5.19 (range $1-13$ ) for 4 alloplastic implants.

\section{DISCUSSION}

As atrophy principally affects the adipose tissue in different grades, the ideal treatment should replace this tissue loss. Both free dermo-fat flap transfer and fat injection achieve this goal.

The groin flap fulfills the requisite of minor donor site morbidity (acceptable scar, no function loss), and natural facial contour, but sometimes it is too bulky and can sag. The radial forearm flap has an advantageous vascular pedicle but is useful only for moderate defects due to the thinness of its adipose 
layer. It also leaves a visible and unpleasant scar especially in women. The parascapular flap is well suited to facial contouring due to the satisfactory subcutaneous layer, it has an excellent pedicle due to its length, large diameter and constant anatomy, and the resulting scar can be considered acceptable. The latissimus dorsi muscle flap has also given good cosmetic results but late muscular atrophy is unavoidable. The possible disadvantages are few: loss of posterior 'push off' movement (getting out of a chair, but in normal conditions muscle function can be well replaced by other muscles), winging of the scapula, donor site pain and seroma formation. An aesthetic disadvantage common to all flap transfers is the visible pre-auricular scar and the skin island used for flap monitoring. Inadequate fixation to the deep dermal layer and periosteum, can result in downward sliding of the transferred flap. To achieve a better cosmetic result with free flaps procedures, it is possible to make a pre-auricular incision that will eventually be like that in a face lift. In this case scars will be less visible. When a skin island is used for flap monitoring or one needs to put in a split thickness skin graft if the free flap has expanded so much as to interfere with the incision, it can be excised later and a return to normal and a face lift type scar obtained. Replacing the laser Doppler monitoring with a Doppler monitor pulse sounds, a skin paddle to follow the free flap will not be necessary.

Lipofilling in the form of microlipo-injection has given satisfactory results. It is important to use a $3 \mathrm{~mm}$ cannula for fat harvesting in order to reduce trauma to the cellular membrane of the adipocytes. We do not filter or wash the harvested fat with Ringer's solution as suggested by Horl et al. (1991). We do not believe it necessary to use 'insulin bathing' or some form of 'systemic reintegration' such as a diet rich in lipids, vitamin $\mathrm{E}$, etc. as suggested by Ellengbogen (1986). We also disagree with Jurkiewicz and Nahai (1985) who criticize fat grafts. Even if it is expected that resorption up to $50 \%$ occurs, the remaining fat, which after almost 8 months is stable and viable and does not resorb further, provides an excellent contour for moderate defects. We have also used this technique in 2 patients with bilateral atrophy; 1 of them, who has been followed for 18 months, has undergone a second session of lipofilling 9 months after the first, achieving a satisfactory result in a severe grade of atrophy. It demonstrates the value of this technique in allowing reconstruction of soft tissue with virtually no contraindications. The procedure can be repeated a number of times, so we do not agree with authors who limit the use to moderate deformities (Horl et al., 1991). Furthermore, the lipofilling technique has the advantages of having no donor area morbidity and leaving no scars on the face. We feel that for good results it is essential to inject not more than $1 \mathrm{cc}$ of fat in any one spot, to isolate each graft from another, thereby avoiding a conglomerate mass of fat that can jeopardize its revascularisation. A further feature of microlipo-injection is that it is not necessary to undermine the recipient area, therefore leaving intact the delicate fasciocutaneous vascular and neuronal plexus. However, in the case of a severe grade of adipose atrophy, because of the low blood supply to these tissues that interferes with the take of any type of autograft, we think that free flaps actually represent one of the best solutions for soft tissue augmentation.

Alloplastic materials can give reasonable results but this was seen in only one of our cases. Complaints of mobility of the prostheses, stiffness and eventual poor cosmesis are more usual. As in 1 of our cases infection is a severe complication necessitating removal of the implant. Fluid silicone injection, actually suspended by FDA, requires long-term investigation before continuing with clinical use (Pearl et al., 1978; Kumagai et al., 1979; Jackson et al., 1986). Polymethylmethacrylate, used in 2 cases, has produced unsatisfactory results difficult to correct at a later date. It was reported (Jackson et al., 1986) that bone grafts are the best material for hard tissue augmentation; because of poor blood supply to these tissues that interfere with any type of autograft, we are not totally in agreement with this author. Other options are the advancement osteotomy and osteogaleal temporal flap (Cutting et al., 1984; van der Meulen et al., 1984; Maillard, 1988).

It is possible to obtain good results in the treatment of the forehead using hydroxyapatite granules (calcium phosphate) or biocoral granules (calcium carbonate) mixed with blood and Avitene (a mycrocristalline polymer form of collagen). It can be placed through a small incision. It works very well and fills both the bony and soft tissue defects. For mandibular defects, good results with Medpore (Porex Co., Atlanta) have been reported, with healing even in the event of infection.

After soft tissue and bone defect correction, treatment can be aimed at the scarred sclerodermalike skin, if present, on the forehead or scalp (alopecia). Tissue expansion represents the best choice in our experience, in accordance with Azzolini et al. (1992).

\section{CONCLUSION}

The correction of soft tissue deformities in patients with PHA using microvascularized flap transfer, lipofilling, or alloplastic implants associated with ancillary procedures, has resulted in a significant morphological improvement in the deformities.

The problem related to this surgery is not the aim of technique but the choice of a technique endowed with less morbidity, reduced costs, and ability to achieve satisfactory cosmetic results. The chosen technique should have minimal operative complications. The use of free flaps requires skilled technique and long operating time, highly specialized surgical and paramedical teams, and high costs. The results, however satisfactory from a general point of view, often have the drawback of creating scars in both donor and facial sites, which sometimes can disturb the overall aesthetic appearance of the patient. Furthermore, free flaps may require further corrections as was necessary for our groin flaps. The microlipo-injection technique 
has no complications at the recipient site such as lesions resulting from dissection, bleeding, necrosis, etc., no facial scars, no donor site morbidity, and it can be performed in a day-hospital, without a highly skilled team, with short surgery time and low costs. The repeatability of the procedure allows us to treat moderate forms of atrophy; however, in the case of severe atrophy, free flaps seem to be the best solution. This same feature is a clear advantage in relation to the nature of the progressive hemifacial atrophy, because one can not exclude with certainty the possibility that the atrophic process may start again after a long remission and that could involve the free flap transfer resulting in failure, whereas the reproducibility of lipofilling can overcome this rare but dramatic event. It can furthermore, represent an interesting procedure for bilateral cases, where it appears excessive to use two free flaps.

\section{References}

Anderl, $H$. .: Free vascularized groin fat flap in hypoplasia and hemiatrophy of the face. (A 3 year observation). J. Max.-Fac. Surg. 7 (1979) 327-352

Antoine, $P h .:$ Fat and dermofat isografts: an experimental study in mice. Eur. J. Plast. Surg. 13 (1990) 247-250

Ashley, F. L., T. D. Rees, D. L. Ballantyne et al.: An injection technique for the treatment of facial hemiatrophy. Plast. Reconstr. Surg. 35 (1965) 640-648

Asken, S. : Facial liposuction and microlipoinjection. J. Dermatol. Surg. Oncol. 14 (1988) 297-305

Azzolini, A., C. Riberti, D. Cavalca: Skin expansion in head and neck reconstructive surgery. Plast. Reconstr. Surg. 90 (1992) 799-807

Billings, E., J. W. May: Historical review and present status of free fat graft autotransplantation in plastic and reconstructive surgery. Plast. Reconstr. Surg. 83 (1989) 368-381

Bruning, P. (1911): Cited by Billings, E., J. W. May: Historical review and present status of free fat graft autotransplantation in plastic reconstructive surgery. Plast. Reconstr. Surg. 83 (1989) 368-381

Chajchir, A., I. Benzaquen, E. Wexler, A. H. Arellano: Fat injection. Aesth. Plast. Surg. 14 (1990) 127-136

Converse, J. M., R.J. Betson: A 20 -year follow-up of a patient with hemifacial atrophy treated by a buried de-epithelialized flap. Plast. Reconstr. Surg. 48 (1971) 278-280

Cutting, C. B., J. G. McCarty, A. Berenstein: Blood supply of the upper craniofacial skeleton: The search for composite calvarial bone flaps. Plast. Reconstr. Surg. 74 (1984) 603-610

Dunkley, M.P., J.H. Stevenson: Experience with the free 'inverted' groin flap in facial soft tissue contouring; a report on 6 flaps. Br. J. Plast. Surg. 4 (1990) 154-158

Ellengbogen, $R$.: Free autogenous pearl fat grafts in the face A preliminary report of a rediscovered technique. Ann. Plast. Surg. 16 (1986) 179-194

Eulenburg, $A$.: Lehrbuch de functionellen Nervenkrankheiten. S. Krager, Berlin, 1871

Fournier, P. F.: Microlipo-extraction et microlipo-injection. Rev. Chir. Esthet. Franc. 10 (1985) 36-40

Franz, P. F., R. Blocksma, S. R. Brundage, S. L. Ringler: Massive injection of liquid silicone for hemifacial atrophy. Ann. Plast. Surg. 20 (1988) 140-145

Fukuta, K., I. T. Jackson, M. V. Collares, Y. Har-Shai, $Y$. Namiki: The volume limitation of the galeal temporalis flap in facial augmentation. Br. J. Plast. Surg. 44 (1991) 281-284

Harashina, T, T. Nakajema, Y. Yoshimura: A free groin flap reconstruction in progressive facial atrophy. Br. J. Plast. Surg. 30 (1977) 14-16

Horl, H. W., A. M. Feller, H. U. Steinau, E. Biemer: Soft tissue contouring using autologous tissue for hemifacial atrophy. Eur. J. Plast. Surg. 14 (1991) 235-239
Hurwitz, P. J., R. Sarel: Facial reconstruction in partial lipodystrophy. Ann. Plast. Surg. 8 (1982) 253-257

Illouz, $Y$. G.: De l'utilisation de la graisse aspiree pour combler les defects cutanes. Rev. Chir. Esthet. Franc. 10 (1985) 13-19

Illouz, $Y . G$. .: The fat cell 'graft': A new technique to fill depressions. Plast. Reconstr. Surg. 78 (1986) 122-123

Jackson, I. T., P. Grothaus, J. M. Ryan, H. Fisher: Treatment options in hemifacial atrophy. Eur. J. Plast. Surg. 9 (1986) $22-28$

Jurkiewicz, M.J., F. Nahai: The use of free revascularized grafts in the amelioration of hemifacial atrophy. Plast. Reconstr. Surg. 76 (1985) 44

Kazanjian, V. H., S. H. Sturgis: Surgical treatment of hemiatrophy of the face. J. A. M. A. 115 (1940) 348-354

Kiskadden, W. S., M.W. McGregor: Report of a case of progressive facial hemiatrophy with pathological changes and surgical treatment. Plast. Reconstr. Surg. 1 (1946) 187192

Kumagai, Y., C. Abe, Y. Shiokawa: Scleroderma after cosmetic surgery: Four cases of human adjuvant disease. Arth. Rheum 22 (1979) 532-537

Lexer, E.: Freie Fetttransplantation. Dtsch. Med. Wochenschr. 36 (1910) 640

Maillard, G. F.: Subperiostal facelift and correction of facial skeleton for severe Romberg fat atrophy. Eur. J. Plast. Surg. 11 (1988) 136-137

Nassif, T. M., L. Vidal, J. L. Bovet, J. Baudet: The parascapular flap: A new cutaneous microsurgical free flap. Plast. Reconstr. Surg. 69 (1982) 561-604

Nerobyeyev, A. I., L. A. Brusova, V. I. Malakhovskaya: Surgical treatment of progressive facial hemiatrophy. Acta Chir. Plast 32 (1990) 65-73

Neuber, G. (1893): Cited by Billings, E., J. W. May: Historical review and present status of free fat graft autotransplantation in plastic and reconstructive surgery. Plast. Reconstr. Surg. 83 (1989) 368-381

Neumann, C. G.: The use of large buried pedicled flaps of dermis and fat in treatment of progressive facial hemiatrophy. Plast. Reconstr. Surg. 11 (1953) 315-332

Parry, C. H.: Collection from the unpublished medical writings of the late Caleb Hillier Parry. Underwoods, London (1825) 478

Pearl, R. M., D. R. Laub, E. N. Kaplan: Complications following silicone injections for augmentation of the contours of the face. Plast. Reconstr. Surg. 61 (1978) 888-891

Peer, L. A.: The neglected free fat graft. Plast. Reconstr. Surg. 18 (1956) 233-250

Peskova, H., B. Stockar: Hemiatrophia faciei progressiva. Acta Chir. Plast. 3 (1961) 276

Pitanguy, I., A. Cansancao, F. Gantijo Texeira: Emprego de mateiriais autogenous no tratamiento das atrofias da face. Rev. Bras. Cir. 61 (1971) 30

Rogers, $B$. O.: Progressive facial hemiatrophy: Romberg's disease; a review of 772 cases. Third Internat. Cong. Plast. Surg. Amsterdam, Excerpta Medica (1964) 681-689

Romberg, $M$. H.: Troponeurosen, Klinische Ergbenisse gesammelt von Heenoch. A. Foerstner, Berlin (1846) 75

Saunders, M.C., J. T. Keller, S. B. Dunsker, F. H. Mayfield. Survival of autologous fat grafts in humans and in mice. Conn. Tissue Res. 8 (1981) 85-91

Sharpe, $C$.: Progressive facial hemiatrophy evaluation of treatment in a case after 9 years. Br. J. Plast. Surg. 24 (1971) 93-96

Smith, A. A., R. T. Manktelow: The use of free tissue transfer to restore facial contour. Clin. Plast Surg., 17 (1990) $\overline{655}$ 661

Sokolova, L. A.: Free adipo-dermal grafts in the surgical treatment of progressive lipodystrophy. Acta Chir. Plast. 14 (1972) 157-165

Upton, J., J.B. Mulliken, P. D. Hicks, J. E. Murray: Restoration of facial contour using free vascularized omental transfer. Plast. Reconstr. Surg. 66 (1980) 560-567

Van der Meulen (1889): Cited by Billings, E., J. W. May: Historical review and present status of free fat graft autotransplantation in plastic and reconstructive surgery. Plast. Reconstr. Surg. 83 (1989) 368-381 
Van der Meulen, J. C., D. J. Hauber, J. M. Vaandrager, D. H. Birgenhager-Frenkel: The use of a temporal osteoperiosteal flap for the reconstruction of malar hypoplasia in TreacherCollins Syndrome. Plast. Reconstr. Surg. 74 (1984) 687-610

Wells, J. H., M. T. Edgerton: Correction of severe hemifacial atrophy with a free dermis-fat flap from the lower abdomen. Plast. Reconstr. Surg. 59 (1977) 223-230
Dr. R. Roddi MD, PhD

Department of Plastic Surgery

University Hospital Rotterdam

Dijkzigt and Sophia Children's Hospital

Dr Molewaterplein, 40

3015 GD Rotterdam

The Netherlands

Paper received 8 March 1993

Accepted 17 August 1993 